\title{
Tuning surface chemistry of TiC electrodes for lithium-air batteries
}

\section{Supporting Information}

\author{
Anna Ya. Kozmenkova, ${ }^{\mathrm{a}, \grave{\ddagger}}$ Elmar Yu. Kataev, ${ }^{\mathrm{a}, \grave{\ddagger}}$ Alina I. Belova, ${ }^{\mathrm{a}}$ Matteo Amati, ${ }^{\mathrm{b}}$ Luca \\ Gregoratti, ${ }^{b}$ Juan Velasco-Vélez, ${ }^{c}$ Axel Knop-Gericke, ${ }^{c}$ Boris Senkovsky, ${ }^{d}$ Denis V. Vyalikh, ${ }^{\text {e,f }}$ \\ Daniil M. Itkis, ${ }^{\mathrm{a}, *}$ Yang Shao-Horn, ${ }^{\mathrm{g}}$ and Lada V. Yashina ${ }^{\mathrm{a}}$ \\ ${ }^{a}$ Lomonosov Moscow State University, Leninskie gory, 119991 Moscow, Russia \\ ${ }^{b}$ Elettra - Sincrotrone Trieste S.C.p.A., Area Science Park, I-34012 Basovizza, Trieste, Italy \\ ${ }^{\mathrm{c}}$ Fritz-Haber-Institut der Max-Planck-Gesellschaft, Faradayweg 4-6, 1495 Berlin, Germany \\ ${ }^{\mathrm{d}}$ Universität zu Köln, Zülpicher Strasse 77, 50937 Köln, Germany \\ ${ }^{\mathrm{e}}$ IKERBASQUE, Basque Foundation for Science, 48011 Bilbao, Spain \\ ${ }^{\mathrm{f}}$ Donostia International Physics Center (DIPC), Departamento de Fisica de Materiales and CFM-MPC UPV/EHU, \\ 20080 San Sebastian, Spain \\ ${ }^{\mathrm{g}}$ Materials Science and Engineering Department, Massachusetts Institute of Technology, Cambridge, Massachusetts \\ 02139, United States
}

Table S1. Calculated standard Gibbs free energy for the reactions of TiC oxidation by $\mathrm{Li}_{2} \mathrm{O}_{2}$. The standard Gibbs free energy of formation of the compounds were taken from NIST-JANAF Thermochemical Tables.
Reaction
$\Delta_{\mathrm{r}} \mathbf{G}^{\mathbf{0}}, \mathbf{k J} / \mathbf{m o l}$
$\mathrm{TiC}+4 \mathrm{Li}_{2} \mathrm{O}_{2} \rightarrow \mathrm{TiO}_{2}+\mathrm{Li}_{2} \mathrm{CO}_{3}+3 \mathrm{Li}_{2} \mathrm{O}$
$-1243.6$
$2 \mathrm{TiC}+6 \mathrm{Li}_{2} \mathrm{O}_{2} \rightarrow 2 \mathrm{TiO}_{2}+\mathrm{Li}_{2} \mathrm{CO}_{3}+\mathrm{C}+5 \mathrm{Li}_{2} \mathrm{O}$
$-1934.8$ 


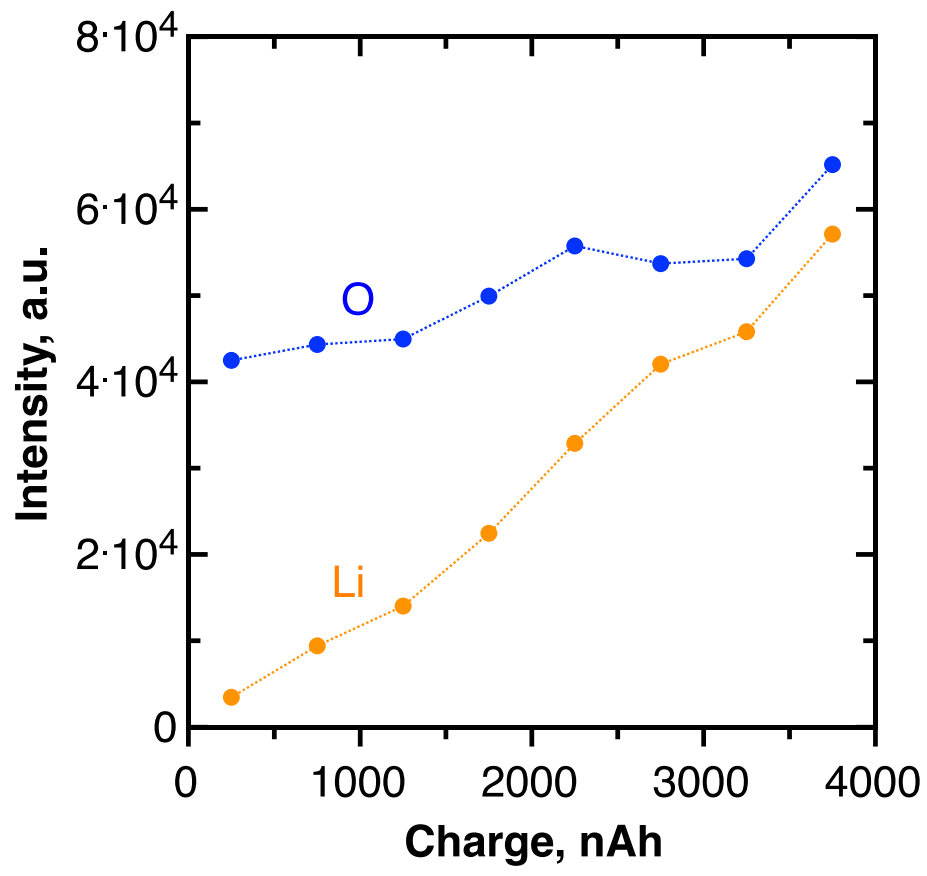

Figure S1. Increase in Li 1s and O 1s peak intensities during galvanostatic discharge of the cell with TiC nanopowder cathode at the current of $1 \mu \mathrm{A}$. The in situ measurements were carried out inside the XPS chamber under 0.1 mbar oxygen pressure. 


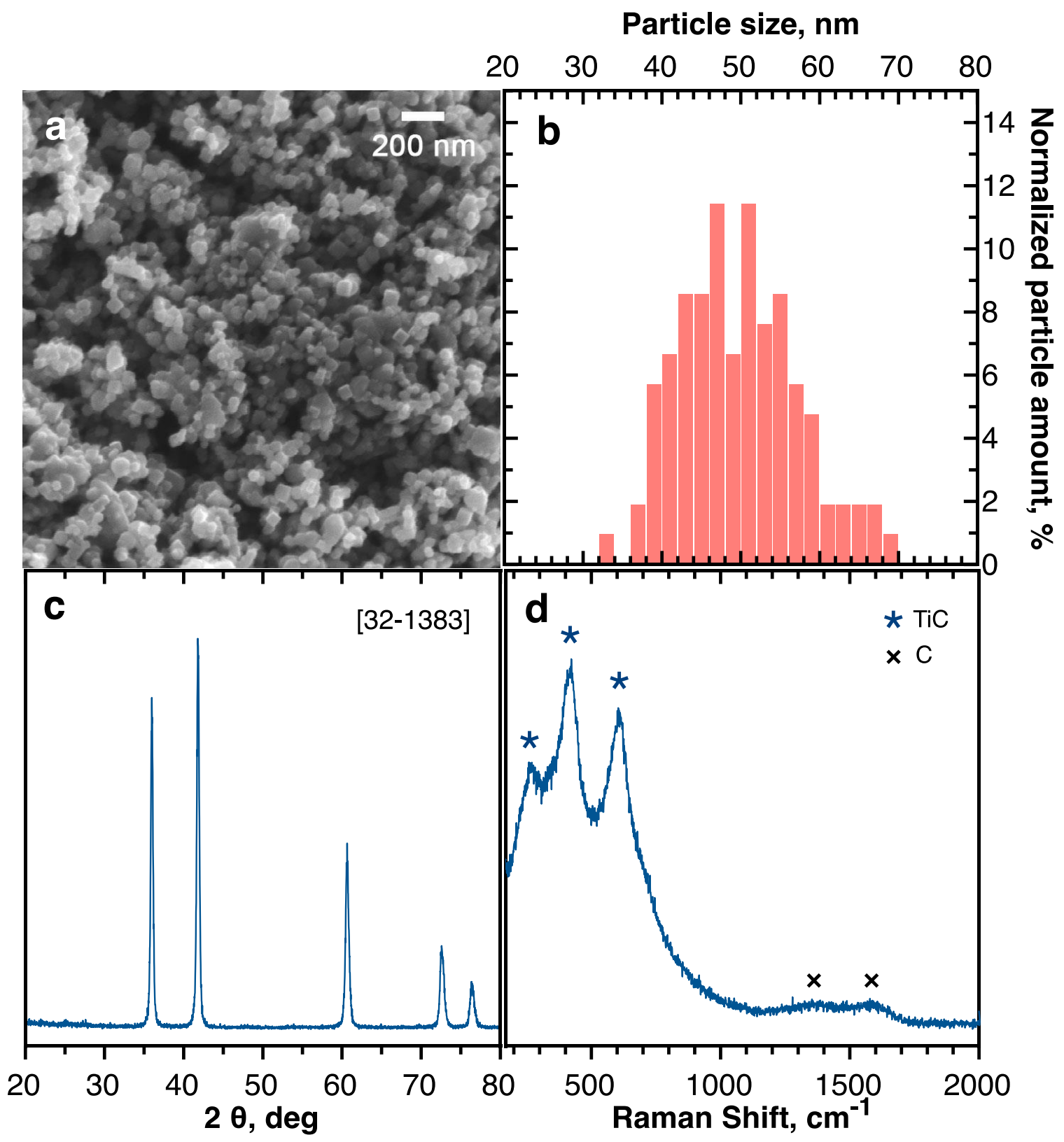

Figure S2. SEM image of TiC nanopowder (a) and its particle size distribution (b). XRD pattern (c) and Raman spectrum (d) confirm that the powder is predominantly composed of TiC with elemental carbon contamination ${ }^{1,2}$.

Calculation of an effective thickness of the discharge product layer formed on the $\mathrm{Ar}^{+}$ sputtered TiC powder electrode during the cell operation.

Formation of the discharge product layer on the $\mathrm{TiC}$ electrode during cell operation results in $\mathrm{Ti}$ $2 p$ intensity attenuation, according to the following equation:

$I=I_{0} \exp \left(-\frac{d}{\lambda \cos \theta}\right)$

where $I-\mathrm{Ti} 2 \mathrm{p}$ intensity for TiC electrode after cell discharge, $I_{0}-\mathrm{Ti} 2 \mathrm{p}$ intensity for initial TiC electrode, $d$-effective thickness of the layer, $\lambda$ - inelastic mean free path of the photoelectrons in the layer, $\theta$-photoelectron emission angle. Thus, for calculation of the effective thickness of 
the discharge product layer Ti $2 p$ intensity in each pixel of the map obtained after cell discharge was divided by Ti $2 p$ intensity in the corresponding pixels of the map from initial TiC electrode, and the result was inserted in the formula above. This procedures were carried out using Igor Pro software.

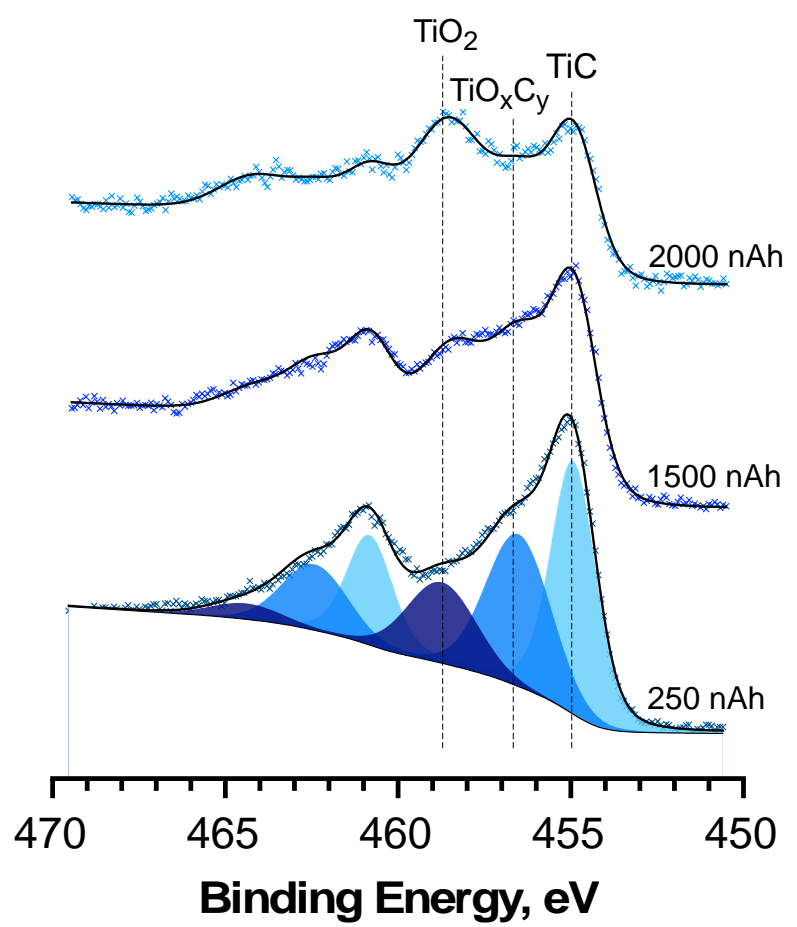

Figure S3. Evolution of $\mathrm{Ti} 2 \mathrm{p}$ spectrum during discharge of the cell with "cleaned" $\mathrm{TiC}$ nanopowder cathode in in situ experiment.

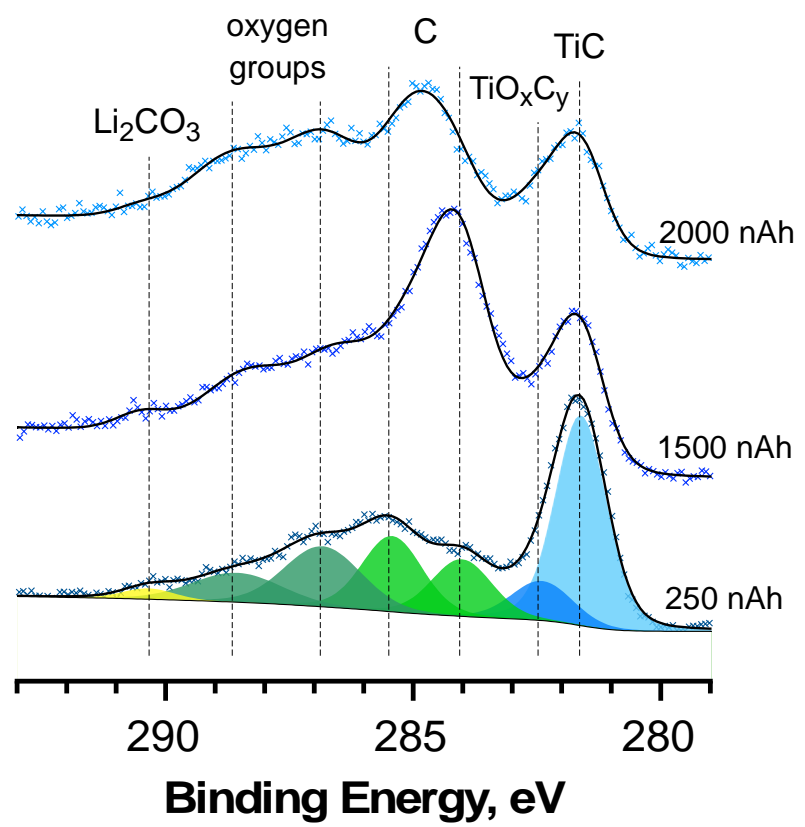

Figure S4. Evolution of C 1s spectrum during discharge of the cell with "cleaned" TiC nanopowder cathode in in situ experiment. 

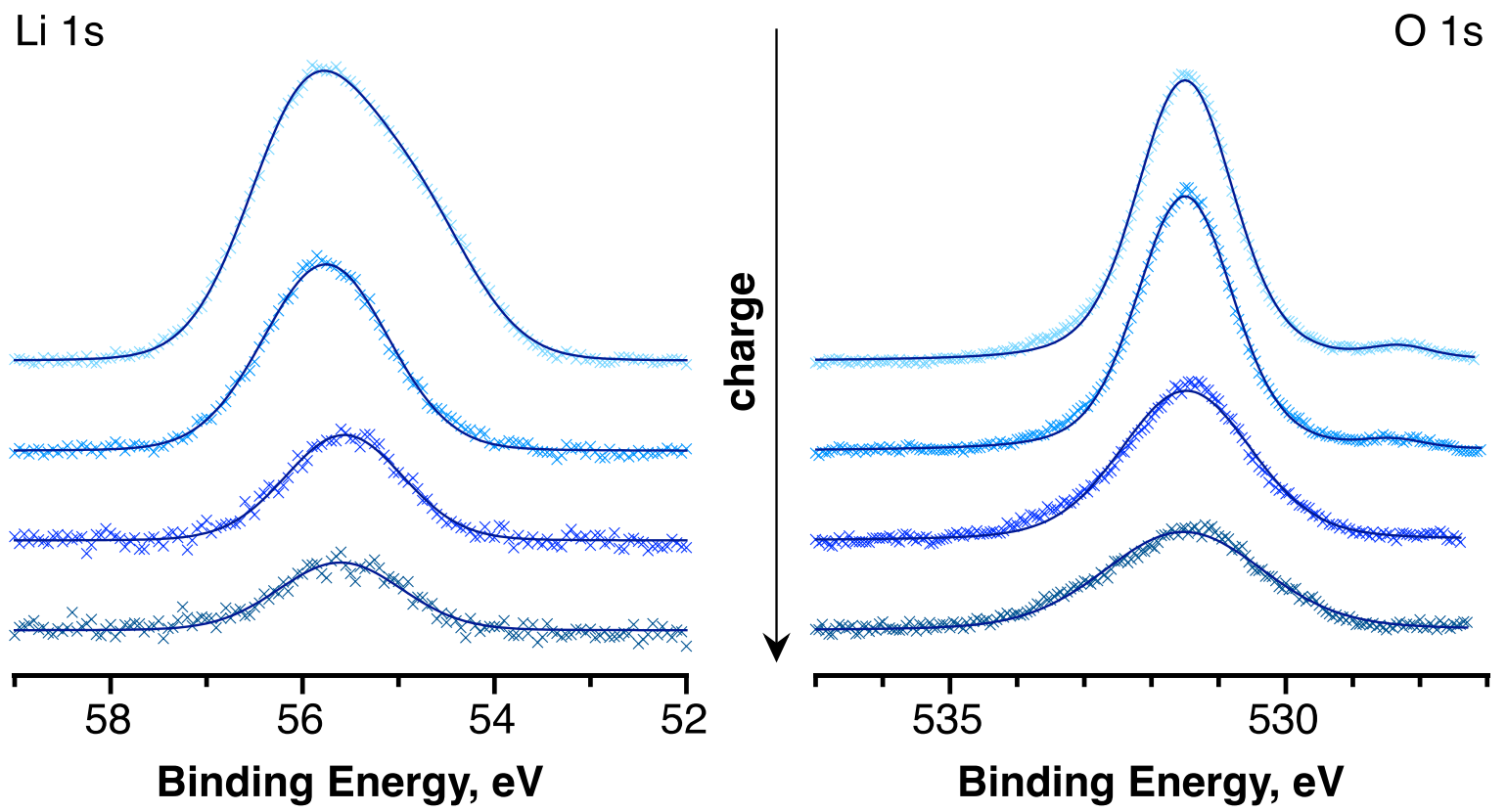

Figure S5. Li $1 \mathrm{~s}$ and $\mathrm{O}$ 1s intensity decrease during charge of the cell with TiC powder electrode, indicating lithium peroxide decomposition. 

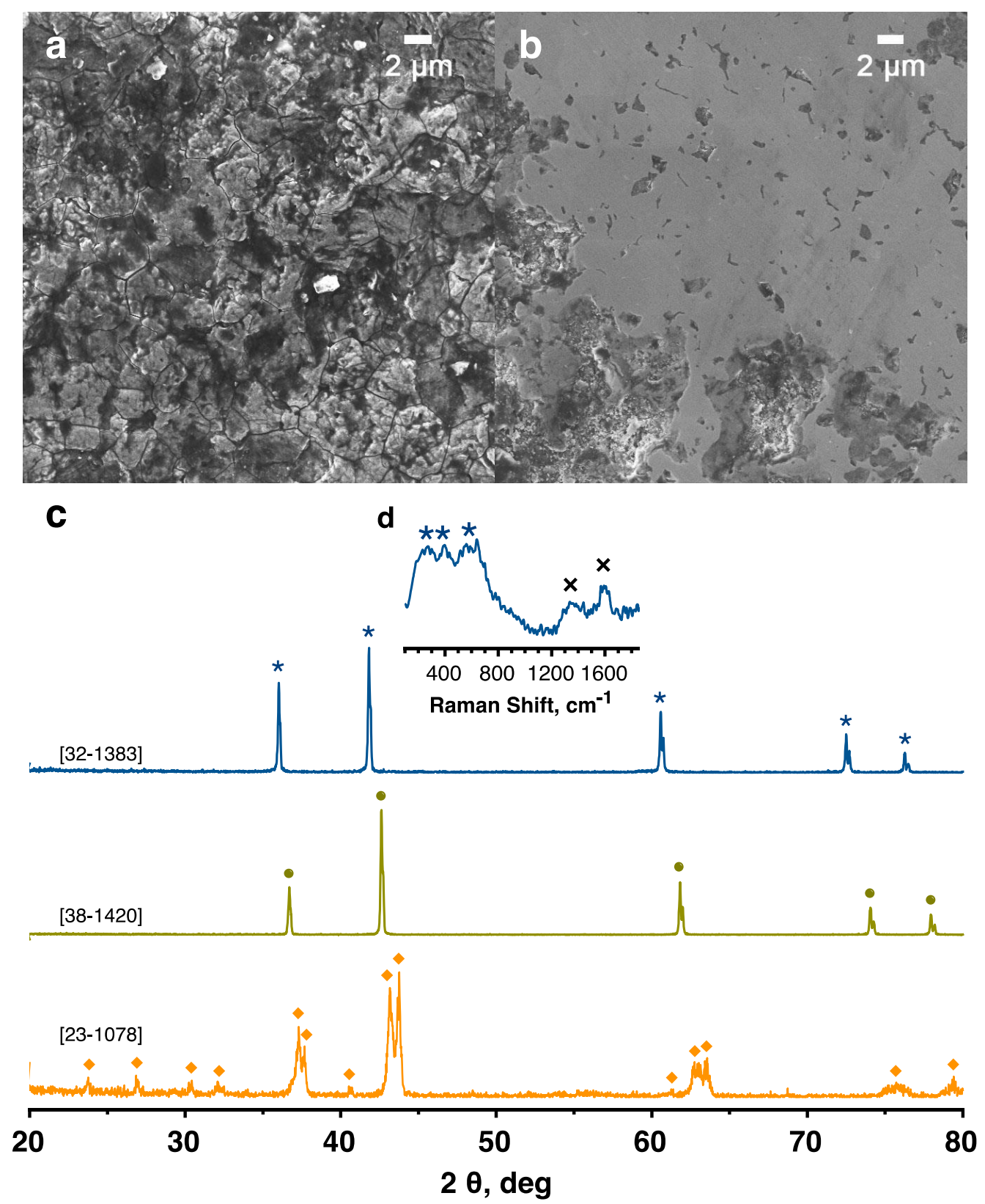

Figure S6. SEM images of the dense ceramic plates, used for TiC, TiN and TiO disc electrodes preparation, before (a) and after (b) polishing. According to XRD patterns (c) and Raman spectrum $(\mathrm{d})$, these plates are single phase $(*-\mathrm{TiC}, \bullet-\mathrm{TiN}, \bullet-\mathrm{TiO})$, except for titanium carbide related, which also contains elemental carbon $(x-C)^{1,2}$. 


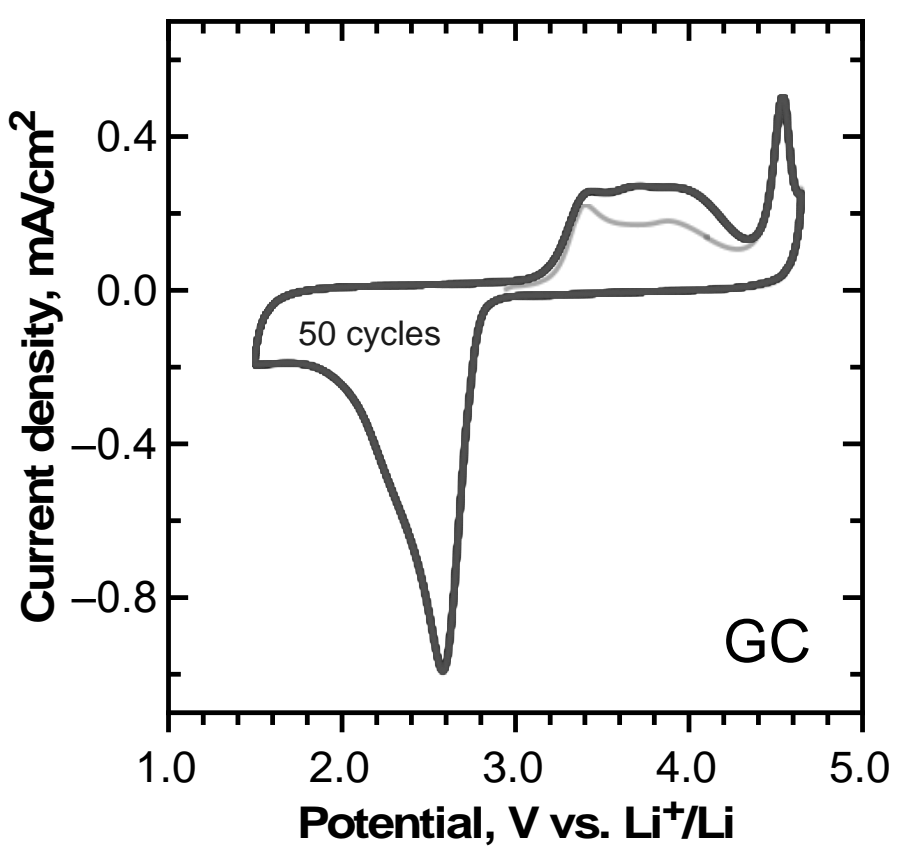

Figure S7. Cyclic voltammogram of glassy carbon polished disc electrode in $1 \mathrm{M}$ LiTFSI solution in DMSO at a sweep rate of $100 \mathrm{mV} / \mathrm{s}$. The processes occurring at cathodic and anodic peak potentials are discussed elsewhere ${ }^{3}$.

\section{Comments to Figure S7}

Three-electrode glass cell used for cyclic voltammetry measurement of glassy carbon (GC) polished disc electrode was assembled in Ar-filled glove box. Pt wire was used as a counter electrode and $\mathrm{Li}$ foil in $1 \mathrm{M} \mathrm{LiClO}_{4}$ solution in propylene carbonate (PC, anhydrous, 99.7\%, Sigma-Aldrich) - dimethoxyethane (DME, anhydrous, 99.5\%, Sigma-Aldrich) mixture as a reference electrode.

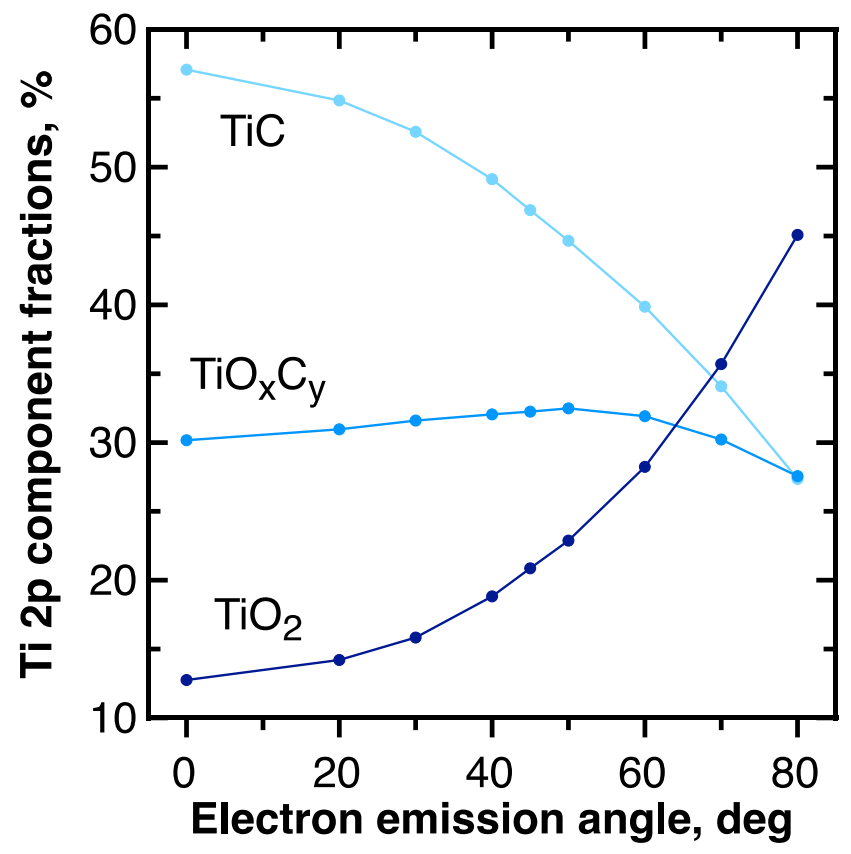

Figure S8. Angle dependence of $\mathrm{Ti} 2 \mathrm{p}$ component relative intensities for the pristine $\mathrm{TiC}$ polished disc electrode. Photoelectron emission angle was measured from the normal to the sample surface. 


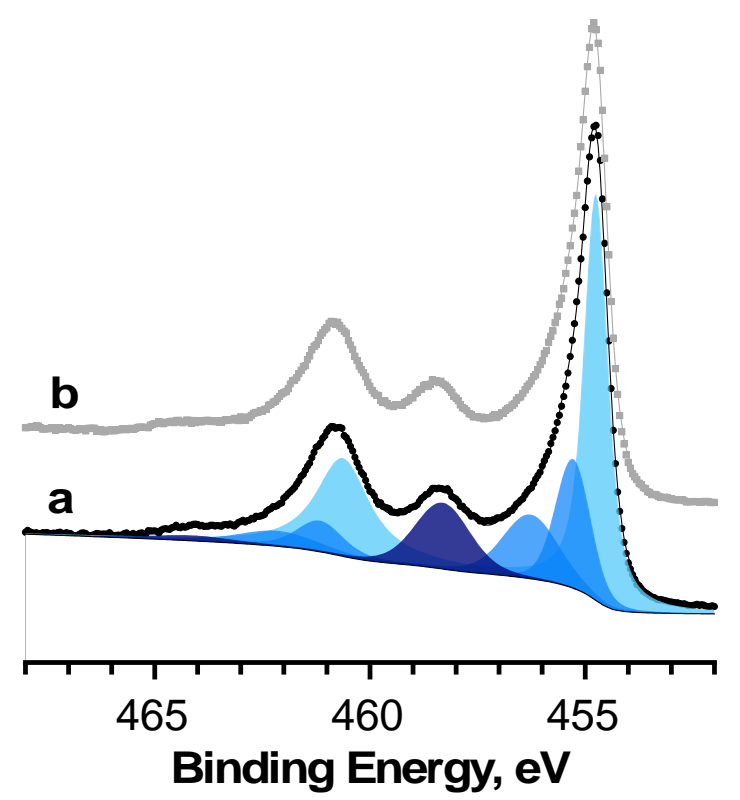

Figure S9. Ti $2 p$ spectra of TiC polished disc electrode pristine (a) and taken after exposure to electrolyte $\left(0.1 \mathrm{M} \mathrm{LiClO}_{4}\right.$ solution in DMSO) (b). The spectra show that $\mathrm{TiC}$ electrode does not undergo any measurable changes in the contact with electrolyte.

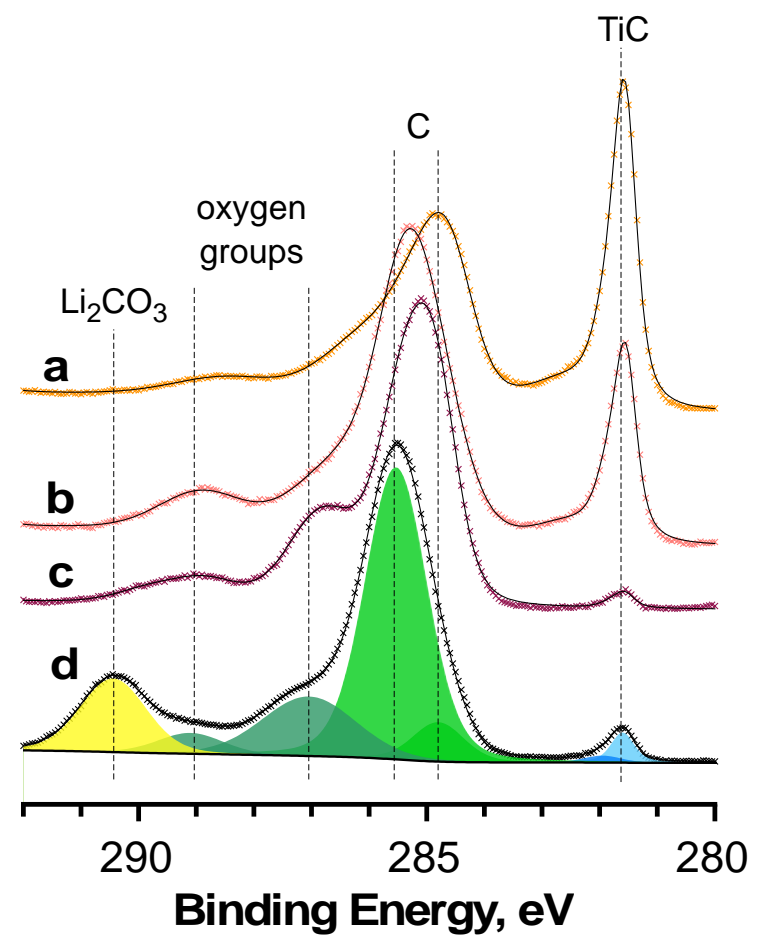

Figure S10. C 1s spectra of pristine TiC polished disc electrode after exposure to electrolyte (a) and the same electrode cycled for 1 (b), 4 (c) and 30 (d) voltammetry cycles. The spectra show the formation and gradual increase of $\mathrm{Li}_{2} \mathrm{CO}_{3}$ amount and the growth of elemental carbon surface layer. 
Calculation of effective $\mathrm{Li}_{2} \mathrm{O}_{2}$ film thickness cathodically generated and anodically oxidized Assuming that lithium peroxide is the main discharge product and anodic charge is spent primarily on $\mathrm{Li}_{2} \mathrm{O}_{2}$ oxidation, we calculated the effective thickness of lithium peroxide film using a combination of Faraday's law and film mass dependence on its thickness that resulted in the following equation:

$d=\frac{M Q}{\rho S n F}$

where $\mathrm{d}$ is the film thickness, $\mathrm{M}$ is the molecular weight of $\mathrm{Li}_{2} \mathrm{O}_{2}, \mathrm{Q}$ is the transferred cathodic/anodic charge, $\rho$ is the density of $\mathrm{Li}_{2} \mathrm{O}_{2}, \mathrm{~S}$ is the TiC electrode area, $\mathrm{n}$ is the number of transferred electrons in ORR/OER, and $\mathrm{F}$ is the Faraday constant. The charge passed during cathodic/anodic process was estimated from cyclic voltammograms by peak analysis procedure in EC-Lab software.

\section{Calculation of surface atomic fractions}

Surface atomic fractions (at\%) of components in $\mathrm{Ti} 2 \mathrm{p}, \mathrm{C} 1 \mathrm{~s}, \mathrm{O} 1 \mathrm{~s}$ and $\mathrm{Li} 1 \mathrm{~s}$ spectra were calculated using the following equations:

$a t \%_{i}=\frac{C_{i}}{\sum_{i} C_{i}}$, where $\mathrm{C}_{i}=\frac{10^{-12} \cdot I_{i}}{k_{i}}$,

where $C_{i}$ is a surface concentration of the component, $I_{i}$ is an integral intensity of the spectral line corresponding to the component, $k_{i}$ is a normalization coefficient for a given line. The values were multiplied by $10^{-12}$ for convenience.

Normalization coefficients were calculated as a product of photon flux and photoionization cross-section for a given photon energy, corresponding to photoelectron kinetic energy of $200 \mathrm{eV}$ (Table S2). The intensity measurements were carried out while synchrotron operated in top-up regime with a constant ring current so no normalization for ring current was applied.

Table S2. The normalization coefficients for atomic fraction calculations.

$\begin{array}{ccccc}\text { Line } & \begin{array}{c}\text { Photon energy, } \\ \text { eV }\end{array} & \text { Flux, a.u. } & \begin{array}{c}\text { Photoionization } \\ \text { cross-section, Mbarn }\end{array} & \text { k, a.u. } \\ \text { Ti 2p } & 665 & 2.009 \mathrm{E}-12 & 0.9413 & 1.891 \mathrm{E}-12 \\ \text { C 1s } & 485 & 3.110 \mathrm{E}-12 & 0.2912 & 0.906 \mathrm{E}-12 \\ \text { O 1s } & 727 & 1.581 \mathrm{E}-12 & 0.2571 & 0.406 \mathrm{E}-12 \\ \text { Li 1s } & 255 & 3.394 \mathrm{E}-12 & 0.1425 & 0.484 \mathrm{E}-12\end{array}$

Calculation of $\mathrm{TiO}_{2}$ surface layer thickness from $\mathrm{Ti} 2 \mathrm{p}$ spectra

Thickness of $\mathrm{TiO}_{2}$ layer (h) on TiC surface was estimated using Hill equation ${ }^{5}$ :

$h=\lambda_{\mathrm{TiO}_{2}} \cos \theta\left(\frac{N_{\mathrm{TiC}} \lambda_{\mathrm{TiC}}}{N_{\mathrm{TiO}_{2}} \lambda_{\mathrm{TiO}_{2}}} \frac{I_{\mathrm{TiO}_{2}}}{I_{\mathrm{TiC}}}+1\right)$, 
where $\lambda_{\mathrm{TiC}}$ and $\lambda_{\mathrm{TiO} 2}$ - inelastic mean free path of the photoelectrons in $\mathrm{TiC}$ and $\mathrm{TiO}_{2}$ at a given photoelectron kinetic energy, $\theta$ - the angle of the photoelectron emission (measured from the normal to the sample surface), $\mathrm{N}_{\mathrm{TiC}}$ and $\mathrm{N}_{\mathrm{TiO} 2}$ - atomic density of $\mathrm{Ti}$ atoms in $\mathrm{TiC}$ and $\mathrm{TiO}_{2}, \mathrm{I}_{\mathrm{TiC}}$ and $\mathrm{I}_{\mathrm{TiO} 2}$ - integral intensity of $\mathrm{TiC}$ and $\mathrm{TiO}_{2}$ related doublets in $\mathrm{Ti} 2 \mathrm{p}$ spectra, normalized by photoionization cross-section and photon flux.

Inelastic mean free path was evaluated using TPP-2M equation (Tanuma, Powell, Penn) ${ }^{6}$ :

$\lambda=\frac{E}{E_{p}^{2}\left[\beta \ln (\gamma E)-C E^{-1}+D E^{-2}\right]}(\AA)$,

where $E_{p}=28.8\left(\frac{N_{v} \rho}{M}\right)^{1 / 2}(e V)$,

$\beta=-0.10+0.944\left(E_{p}^{2}+E_{g}^{2}\right)^{-0.5}+0.069 \rho^{0.1}$,

$\gamma=0.191 \rho^{-0.50}$

$C=1.97-0.91 U$,

$D=53.4-20.8 U$

$U=\frac{N_{v} \rho}{M}=\frac{E_{p}^{2}}{829.4}$

$E$ is the kinetic energy of photoelectrons, $E_{p}$ is the free-electron plasmon energy, $N_{v}$ is the number of valence electrons per molecule, $\rho$ is the density (in $\mathrm{g} / \mathrm{cm}^{3}$ ), $\mathrm{M}$ is the molecular weight, and $\mathrm{E}_{\mathrm{g}}$ is the bandgap energy (in eV).

Table S3. The coefficients for $\mathrm{TiO}_{2}$ surface layer thickness calculation.

$\lambda, \AA(200 \mathrm{eV}) \quad \mathrm{N} / \mathrm{N}_{\mathrm{A}}, \mathrm{mol} / \mathrm{cm}^{3}$

$\begin{array}{lll}\mathrm{TiC} & 6.68 & 0.082\end{array}$

$\begin{array}{lll}\mathrm{TiO}_{2} & 7.30 & 0.053\end{array}$ 


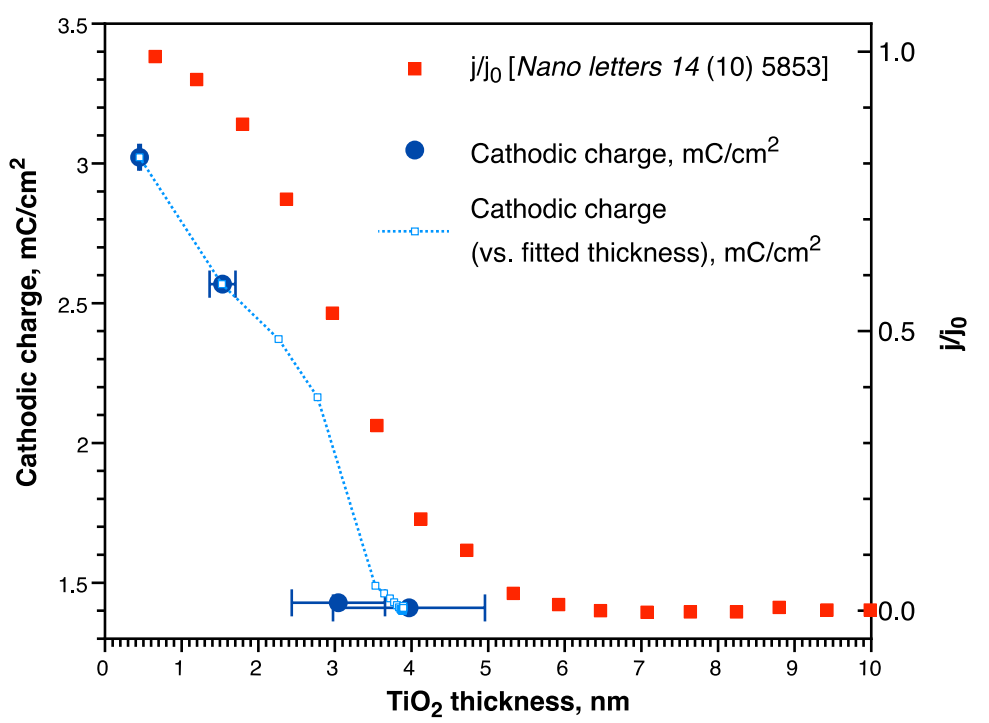

Figure S11. The dependencies of cathodic charge and theoretical relative current density ${ }^{7}$ on $\mathrm{TiO}_{2}$ layer thickness. Experimental $\mathrm{TiO}_{2}$ layer thickness determination by XPS was performed after selected cycles (dark blue circles). Light blue open squares indicate cathodic charge dependence on $\mathrm{TiO} 2$ thickness determined from fitting of experimentally obtained thickness values vs. cycle number.

\section{Calculation of a transfer coefficient $(\alpha)$}

Transfer coefficient was calculated for the first step of oxygen reduction reaction (ORR) resulting in superoxide species formation:

$\mathrm{O}_{2}+\mathrm{e}^{-} \rightarrow \mathrm{O}_{2}^{-}$

For this purpose, Tafel plot (E vs. ln |i|) was obtained from the voltammetry curve and fitted by the straight line (figure S12a). A value of this line slope was used to estimate the transfer coefficient, according to the following equation:

$$
E=\frac{R T}{\alpha n F} \ln i_{0}+E_{e q}-\frac{R T}{\alpha n F} \ln |i|
$$

where $\mathrm{E}$ is the working electrode potential, $\mathrm{R}$ is the molar gas constant, $\mathrm{T}$ is the temperature, $\mathrm{n}$ is the number of electrons transferred in observed electrochemical reaction, $\mathrm{F}$ is the Faraday constant, $i_{0}$ is the exchange current density, $E_{\text {eq }}$ is the equilibrium potential of the reaction, and $i$ is the current density on the working electrode.

Figure S12b shows the variation of the transfer coefficient for above-mentioned reaction occurring on the polished $\mathrm{TiC}$ disc electrode surface at room temperature upon voltammetric cycling, indicating nearly the same value of $0.54 \pm 0.06$. 

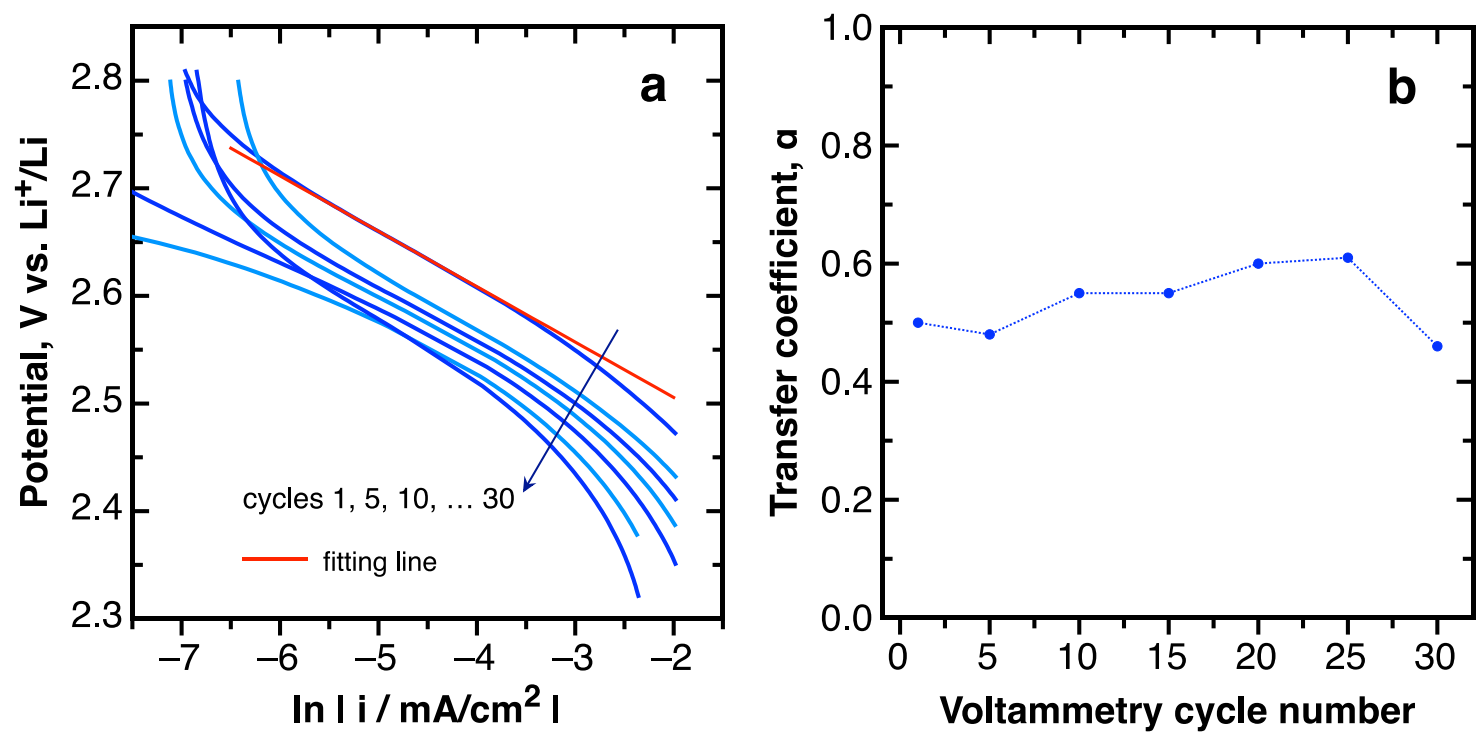

Figure S12. (a) Tafel plot for the fist step of ORR on the $1^{\text {st }}, 5^{\text {th }}, 10^{\text {th }}, 15^{\text {th }}, 20^{\text {th }}, 25^{\text {th }}$ and $30^{\text {th }}$ voltammetric cycles measured at a sweep rate of $100 \mathrm{mV} / \mathrm{s}$ on the polished TiC disc electrode in $0.1 \mathrm{M} \mathrm{LiClO}_{4}$ solution in DMSO; (b) the variation of the transfer coefficient for the first step of ORR occurring on this electrode with cycle number.

\section{References}

(1) Klein, M. V.; Holy J. A.; Williams W. S. Phys. Rev. B 1978, 17, 1546.

(2) Lohse, B. H.; Calca, A.; Wexler, D. J. Appl. Phys. 2005, 97, 114912.

(3) Laoire, C. O.; Mukerjee, S.; Abraham, K. M.; Plichta, E. J.; Hendrickson, M. A. J. Phys. Chem. C 2010, 114, 9178.

(4) Yeh, J. J.; Lindau, I. Atomic Data and Nuclear Data Tables 1985, 32, 1.

(5) Cumpson, P. J.; eds. Briggs, D. and Grant, J. T. IM Publications and Surface Spectra Ltd., Chichester 2003.

(6) Tanuma, S.; Powell, C. J.; Penn, D. R. Surf. Interface Anal. 1994, 21, 165.

(7) Viswanathan, V.; Pickrahn, K. L.; Luntz, A. C.; Bent, S. F.; Nørskov, J. K. Nano letters 2014, 14 (10), 5853. 